\title{
A Case Report
}

\section{Better outcome in pulpotomy on primary molar with Biodentine}

*Asma sultana ${ }^{\mathrm{a}}$, Fahd A.A Karim ${ }^{\mathrm{b}}$, (Major) Md. Abdul Hannan Sheikh ${ }^{\mathrm{c}}$, Mohammad Wahiduzzaman ${ }^{\mathrm{d}}$, Md.Shamsul Alam ${ }^{\mathrm{e}}$, Mahabubul Hossain ${ }^{\mathrm{f}}$,

a. Assistant professor and Head, Department of Science of Dental Materials, Update Dental College\& Hospital.

b. Assistant Professor Dept of Conservative dentistry \& Endodontics, Update Dental College \& Hospital.

c. Graded Specialist in Conservative Dentistry \& Endodontics, CMH, Savar Cantt.

d. FCPS trainee, Department of Conservative Dentistry \& Endodontics, BSMMU, Dhaka.

e. Professor \& Chairman, Dept of Conservative Dentistry \& Endodontics, Dean faculty of Dentistry, BSMMU, Dhaka.

f. Lecturer, Department of Conservative Dentistry \& Endodontics, Update Dental College \& Hospital.

\section{ARTICLE INFO}

Article history:

Received : 20.07.15

Accepted : 19.09.15

Key words:

Biodentin, Acute reversible

pulpitis, Pulpotomy

\begin{abstract}
Aim: The primary objective of any pulp therapy is to maintain the integrity and health of a tooth and its supporting tissue as well as to maintain arch length and space maintenance. The aim of this case is to a probate and popularizes the technique of vital pulpotomy in primary teeth with biodentin.
\end{abstract}

\section{Introduction:}

Preservation of primary teeth before the eruption of permanent teeth is desirable since they help to determine the shape of dental arches, maintain the space between teeth, prevent detrimental tongue, speech habits ,preserve aesthetics and maintain chewing function. However there are varying opinions about how to manage primary teeth when the pulp has been exposed by caries or through mechanical procedures. ${ }^{1}$ The possible choices for conservative pulp therapy are direct pulp capping, pulpotomy, pulpectomy. A pulpotomy is based on the hypothesis that the inflammation and reduced vascularization, caused by bacterial invasion, are confined to the coronal pulp, while the root pulp remains vital. $^{2}$

\footnotetext{
Correspondence to:

Dr. Asma Sultana BDS,DDS

Assistant Professor \& Head

Dept. of Science of Dental materials

Update Dental College and Hospital, Dhaka

Mobile: 01817515508

Email:asmakarim08@gmail.com
}

\section{CASE:}

A 6 years old girl came to BSMMU with complaints of pain for 2 days on her right lower jaw. Clinical examination illustrated extensive deep caries in the mandibular right deciduous molar. The tooth was sensitive to cold. No visible swelling and sinus tract was found. Radiological examination revealed that the tooth has no periapical pathology. The case was diagnosed as a case of acute reversible pulpitis due to caries. Treatment procedure was planed pulpotomy on lower right 2 nd primary molar.

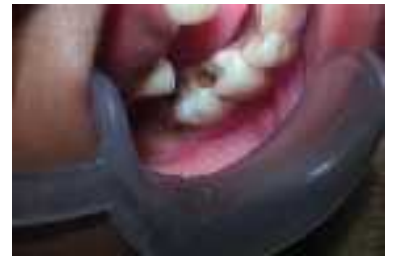

Fig 1:Deep caries on $2^{\text {nd }}$ primary molar

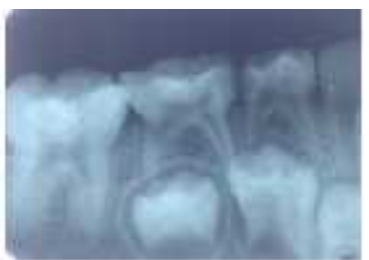

Fig2: Pre operative X-ray showing carious lesion mesially involving the pulp. 
The methodology is one visit and was performed following this clinical protocol. Disinfection of the operative field and proper sterilization of instruments was ensured. After proper isolation of teeth and with the use of saliva ejector inferior alveolar nerve block (2\% lidocaine) as local anesthesia was administration for effective pain control. Firstly, surrounding caries was removed and the pulp chamber was accessed with bur No 330 high speed hand piece with water spray. Following removal of the coronal pulp with an sterile excavator, pulp chamber rinsed with normal saline, homeostasis was obtained by slightly moistened sterile cotton pellets soaked in saline solution for 2-3 minutes. Mix biodentine according to manufacturer's directions to a paste-like consistency, fill the chamber and packing was done gently over amputated pulp orifice. The material applied deep within the cavity with amalgam carrier and compacted using cotton pellets. Finally the tooth was restored with glassionomer base and composite filling. Post operative radiograph will be taken.

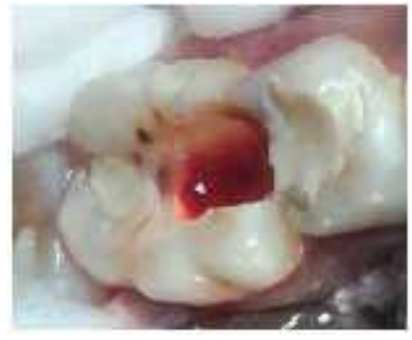

Fig3: Access to pulp chamber with

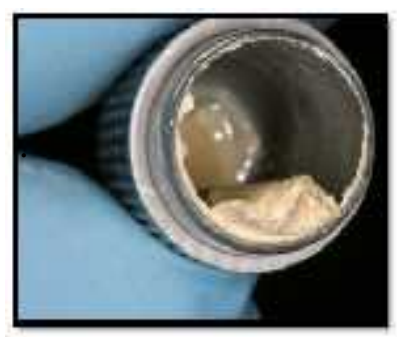

Fig5: Mixed biodentine to a paste like consistency of biodentine High speed hand piece no 330 bur.

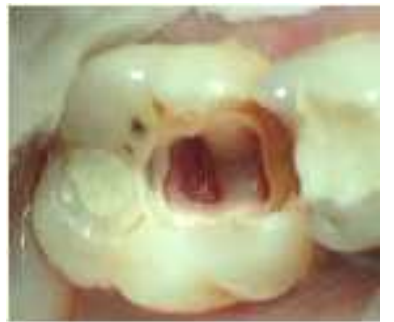

Fig4:Removal of coronal pulp and Homeo stasis obtained using moistened cotton pellet

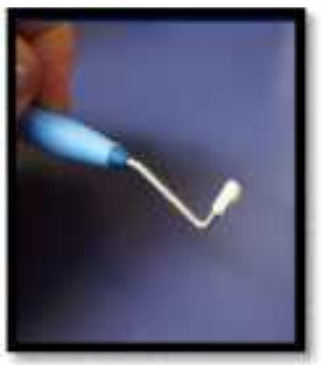

Fig6: Aapplication

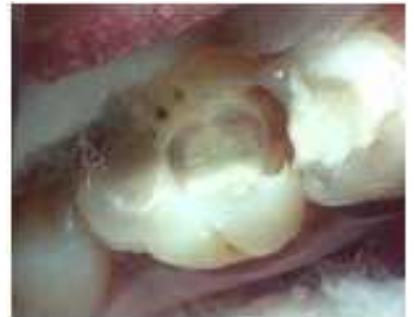

Fig7: Fill the chamber with biodentine.

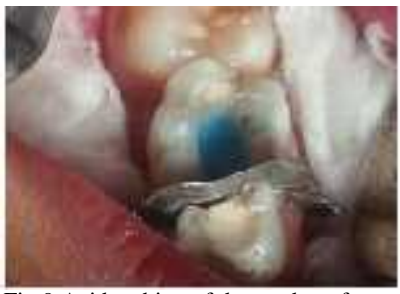

Fig:9 Acid etching of the tooth surface.

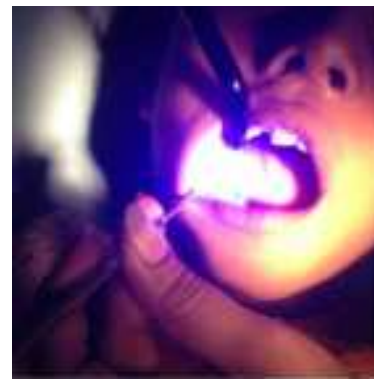

Fig:UV light curing of composite resin.

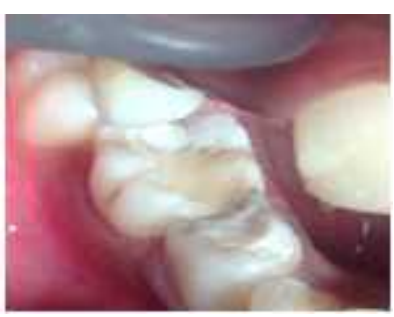

Fig:10 Final polishing and finishing

of composite restoration.

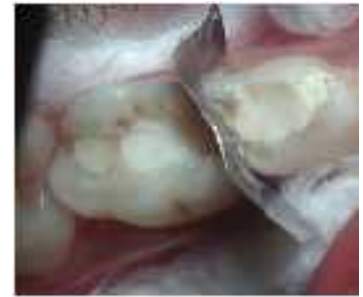

Fig8:Application of GIC base over biodentine.

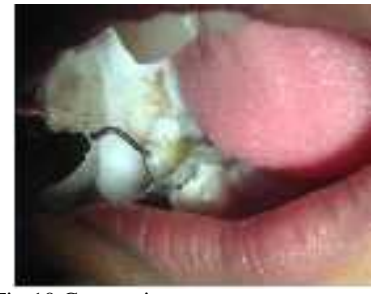

Fig:10 Composite

application to restore the cavity.

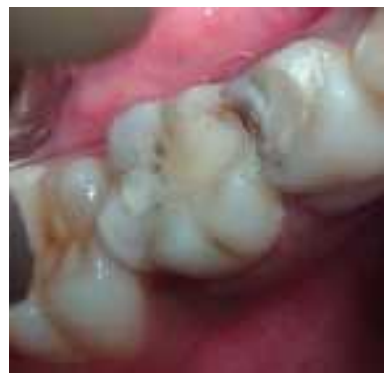

Fig: After curinng of composite

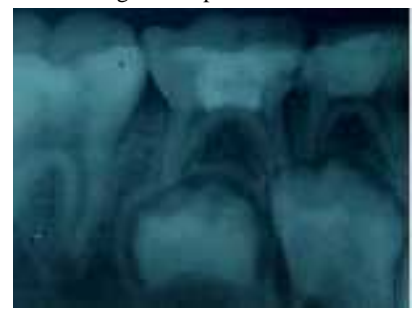

Fig: Post operative radiograph showing radiopacity (due to biodentine GIC and Composite ) on the crown area
Patient was recalled every 1 months, 3 months, 6 months, 9 months and 12 months interval.After 1 year tooth was functional with no signs and symptoms both clinically and radiologically.

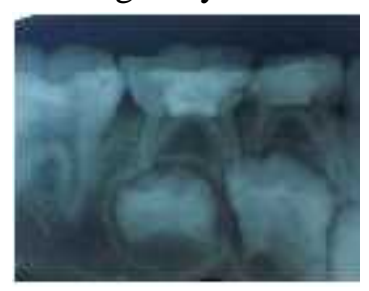

Fig: 1 month follow up.

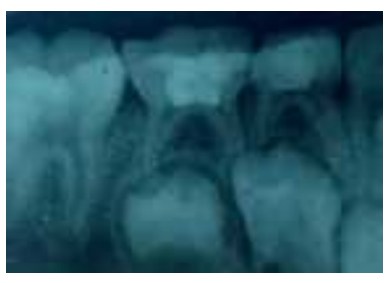

Fig: 3months follow up 


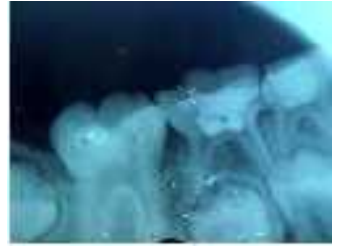

Fig : 6 months follow

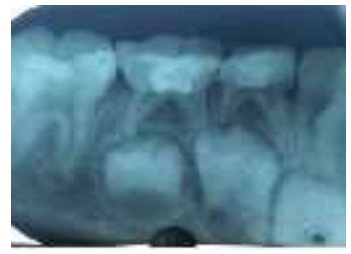

Fig: 1 year follow up

\section{Discussion:}

Pulpotomy technique basically consists of removing the coronal pulp and fixing the radicular pulp with a medicament. It is the most widely accepted clinical procedure for treating primary teeth with coronal pulp inflammation caused by caries with no involvement of the radicular pulp.Over the years, many different medicaments, pulp dressings, and techniques have been used in pulp therapy procedures. Formocresol, ferric sulfate, calcium hydroxide, glutaraldehyde, mineral trioxide aggregate, laser therapy, and electro surgery have all been used with varying degrees of success. ${ }^{3}$ The most widely used medicament in North America and the United Kingdom is formocresol. ${ }^{4,5}$ It has been described as the gold standard of pulp therapy. ${ }^{6}$ However, there have been significant concerns for the past 25 years surrounding the use of formocresol as a pulpotomy medicament. $^{7}$ More insistently, the current studies present information and guidelines for limitation on formocresol technique for vital amputation because of the evidence gained from animal testing that mutagenic, carcinogenic, immunogenic and toxicity potential of formaldehyde. $8,9,10,11$ and the World Health Organization classified formocresol as a known carcinogen. ${ }^{12}$ As the debate continues, it would behoove dental professionals to search out a reliable biocompatible medicament or technique for vital pulp therapy. Mineral trioxide aggregate (MTA) has been documented extensively and is a viable option for a biocompatible material for pulp therapy. ${ }^{13,14,15,16,17}$ During the past several years, special attention has been paid to MTA usage in endodontic treatment of permanent teeth ${ }^{17,18,19,20,21}$ as well as probable alternative of formocresol in primary teeth vital primary teeth. ${ }^{22,23,24,25,26}$ But there are some shortcoming of MTA which are difficult handling, long setting time, and potential discoloration. Portland cement (PC) has a similar composition and biologic effect to MTA, but needs further investigation before it can be used in dentistry. ${ }^{27,28}$

Recently, with improvement of medicaments, that are not only biocompatible, but also bioinductive, the focus has been directed from preservation and conservation to regeneration of the remaining pulp tissue. ${ }^{24,25,29}$ Calcium silicate-based material, which called Biodentine ${ }^{\circledR}$ is a new option composed of tricalcium silicate that has been described as a dentin replacement material. It has properties similar to PC and MTA, ${ }^{30,31}$ Biodentine has the potential to induce apposition of reactionary dentin by stimulating odontoblasts and reparative dentin by induction of cell differentiation. ${ }^{15,32}$ The $\mathrm{pH}$ of Biodentine is very high $(\mathrm{pH}=12)$, giving it bacteriostatic properties. It also has the ability to form a good marginal seal. Finally, Biodentine handles with a creamy, rather than sandy, texture and it sets completely within 12 minutes. ${ }^{33}$ This material is new biologically active cement which has dentine-like mechanical properties. Unlike other Portland cement-based products, it is sufficiently stable so that it can be used both for pulp protection and temporary fillings. ${ }^{34}$ The manufacturer claimed about the biocompatibility and the bioactivity of the material, which is important when used as indirect and direct pulp capping and pulpotomy. Furthermore, it preserves pulp vitality and promotes its healing process. British Journal of Medicine \& Medical Research, assessed the biological effects of Biodentine for use in pulp-capping treatment, on pseudo-odontoblastic (MDPC-23) and pulp (Od-21) cells. Secondly, the same authors evaluated the effects of Biodentine and MTA on gene expression in cultured spheroids. They 
concluded that Biodentine and MTA may modify the proliferation of pulp cell lines. ${ }^{35}$

According to the manufacturer, Biodentine consists of a powder in a capsule and liquid in a pipette. The powder mainly contains tricalcium and dicalcium silicate, the principal component of Portland cement, as well as calcium carbonate. Zirconium dioxide serves as contrast medium. The liquid consists of calcium chloride in aqueous solution with an admixture of polycarboxylate.

Biodentine was shown to be biocompatible, i.e. it does not damage pulpal cells in vitro or in vivo, and is capable of stimulating tertiary dentin formation. Hard tissue formation is seen both after indirect and direct capping with Biodentine. Compared the biocompatibility of Biodentine with that of MTA and a hardening calcium hydroxide. They reported that Biodentine is biocompatible. ${ }^{31}$ The bioactivity of this material, demonstrating the formation of hydroxyl apatite when immersed in phosphate solution. ${ }^{36}$ Bioactivity of it is confined by studying its effects on pulp progenitor cells activation, differentiation and dentine regeneration in human tooth cultures. They concluded that Biodentine is stimulating dentine regeneration by inducing odontoblast differentiation from pulp progenitor cells. ${ }^{37}$ The capacity of Biodentine to induce reparative dentin synthesis by modulating pulp cells to secrete transforming growth factorbeta 1 (TGF-ß1) and stimulate human dental pulp mineralization. ${ }^{38}$ Histologically, the bioactive tricalcium silicate demonstrated the ability to induce odontoblast differentiation from pulp progenitor cells. The resulting mineralized matrix had the molecular characteristics of dentine. Biodentine is stronger mechanically, less soluble and produces tighter seals. This qualifies it for avoiding three major drawbacks of calcium hydroxide, i.e. material resorption, mechanical instability and the resultant failure of preventing microleakages.. When used as a dentine replacement material in the sandwich technique overlayed with composite, significant leakage occurred at the dentine to material interface. On the other hand materials based on glass ionomer cement were etched successfully and no chemical and physical changes or micro-leakage were detected when the materials were used as bases under composite restorations. The micro-hardness of all the materials was unaffected by etching. During the setting phase of Biodentine, calcium hydroxide ions are released from the cement. This results in a $\mathrm{pH}$ of about 12.5 and a basification of the surroundings. This high $\mathrm{pH}$ inhibits the growth of microorganisms and can disinfect the dentine. ${ }^{39}$

\section{CONCLUSIONS:}

Biodentine is a clinically practical material for vital pulp therapy in primary molars. It holds promise for clinical dental procedures as a biocompatible, bioactive and easily handled product with short setting time comparison with other similar materials. Due to this major advantages and appreciable properties and ability to achieve biomimetic mineralisation, biodentine has great potential to revolutionise the management of affected tooth in the operative dentistry. Biodentine pulpotomy is a simple technique for reliable biocompatible vital pulp procedure. So this study was an attempt to evaluate biodentin as a reliable pulpotomy agent in future. As more research is performed regarding this interesting alternative to MTA, we will provide with more reliable data and more confidently implement of Biodentine into routine clinical applications in future.

\section{REFERNCE:}

1. Barr ES, flaitz CM, Hicks MJ. A retrospective evalution of primary molar pulpectomies. pediatr.Dent 1991; 13:4-9

2. Guidelines. american academy of Pediatric Dentistry. Pediatric dentistry. 1996;18(6):30 81. epub 1996/11/01. 
3. American Academy of Pediatric Dentistry. Guideline on pulp therapy for primary and immature permanent teeth. Reference Manual. 2012/2013; 34(6):222-229.

4. Hunter ML, Hunter B. Vital pulpotomy in the primary dentition: attitudes and practices of specialists in paediatric dentistry practising in the United Kingdom. Int $J \quad$ Paediatr Dent. 2003;13(4):246-250.

5. Primosch RE, Glomb TA, Jerrell RG. Primary tooth pulp therapy as taught in pediatric dental programs in the United States. Pediatr Dent. 1997;19(2):118-122

6. King SR, McWhorter AG, Seale NS. Concentration of formocresol used by pediatric dentists in primary tooth pulpotomy. Pediatr Dent. 2002;24(2):157159.

7. Casas MJ, Kenny DJ, Judd PL, Johnston DH. Do We still need formocresol in paediatric dentistry? J Can Dent Assoc. 2005; 71(10):749-751.

8. Hunter ML, Hunter B.: Vital pulpotomy in the primary dentition attitudes and practices on specialists in paediatric dentistry practicing in the United Kingdom. Int $\mathbf{J}$ Paediatr Dent 2003 13: 246-250 .

9 Lewis B.: Formaldehyde in Dentistry: A Review for the Millenium. J Clin Pediatr. Dent 1998; 22: 177 - 186

10. Ranly DM., Garsia-Godoy F.: Current and Potential Pulp Therapies for Primary and Young Permanent Teeth. J Dent 2000; 28: 153-161

11. Srinivasan V., Patchett CL., Waterhouse PJ.: Is there Life after Buckley's Formocresol? Part I - a Narrative Review of Alternative Interactions and materials. Int $\mathbf{J}$ Ped Dent 2006; 16: 117-127

12. IARC classifies formaldehyde as carcinogenic to humans [press release]. Lyon, France: International Agency for Research on Cancer.june15,2004

13. Caicedo R, Abbott PV, Alongi DJ, Alarcon MY. Clinical, radiographic and histological analysis of effects of mineral trioxide aggregate used in direct pulp capping and pulpotomies of primary teeth. Aust Dent J. 2006;51(4):297-305.

14. Erdem AP, Guven Y, Balli B, et al. Success rates of mineral trioxide aggregate, ferric sulfate, and formocresol pulpotomies: a 24-month study. Pediatr Dent2011;33(2):165-170.

15. Ansari G, Ranjpour M. Mineral trioxide aggregate and formocresol pulpotomy of primary teeth: a 2-year follow-up. Int Endod J. 2010;43(5):413-418.

16. Doyle TL, Casas MJ, Kenny DJ, Judd PL. Mineral trioxide aggregate produces superior outcomes in vital primary molar pulpotomy. Pediatr Dent. 2010;32(1):4147.

17. Godhi B, Sood PB, Sharma A. Effects of mineral trioxide aggregate and formocresol on vital pulp after pulpotomy of primary molars: an in vivo study. Contemp Clin Dent. 2011;2(4):296301.

18. Barrieshi-Nusair KM, Qudeimat MA.: A prospective clinical study of mineral trioxide aggregate for partial pulpotomy in cariously exposed permanent teeth. $\mathbf{J}$ Endod 2006; 32: 731-735.

19. El-Meligy OA, Avery DR.: Comparison of mineral trioxide aggregate and calcium hydroxide as pulpotomy agents in young permanent teeth (apexogenesis) Pediatr Dent 2006; 28: 399- 404.

20. Srinivasan V., Waterhouse P., Whitworth $\mathrm{J} .:$ Mineral trioxide aggregate in paediatric dentistry. International Journal of Paediatric Dentistry 2009; 19: 34-47

21. Subramaniam P., Konde S., Mathew S., Sugnani S: Mineral trioxide aggregate as pulp capping agent for primary teeth pulpotomy: 2 year follow up study. J Clin Pediatr Dent.; 2009: 33(4):311-4 .

22. Aeinehchi M, Dadvand S, Fayazi S, BayatMovahed S.: Randomized controlled trial of ièiềàë trioxide aggregate àd 
formocresol for pulpotomy in primary molar teeth. Int Endod J 2007; 40: 261267. 22. 23. 23. Agamy HA, Bakry NS, Mounir MMF, Avery DR.: Comparison of mineral trioxide aggregate and formocresol as pulpcapping agents in pulpotomized primary teeth. Pediatr Dent 2004; 26: 302-309.

24. Eidelman E, Holan G, Fuks AB.: Mineral trioxide aggregate vs. formocresol in pulpotomized primary molars: a preliminary report. Pediatr Dent 2001; 23: 15-18.

25. Farsi N., Alamoudi N., Khalid Balto K., Mushayt A.: Success of mineral trioxide aggregate in pulpotomized primary molars. J Clin Pediatr Dent 2005; 29(4): 307-312 .

26. Holan G., Eidelman E., Fuks A.B.: Longterm Evaluation of Pulpotomy in Primary Molars Using Mineral Trioxide Aggregate or Formocresol. Pediatric Dentistry 2005; 27(2): 129-136

27 .Shayegan A, Jurysta C, Atash R, et al. Biodentine used as a pulp-capping agent in primary pig teeth. Pediatr Dent. 2012;34(7):e202-e208.

28. Sakai V, Moretti A, Oliviera $\mathrm{T}$, et al. Pulpotomy of human primary molars with MTA and Portland cement: a randomised controlled trial. $\mathrm{Br}$ Dent J. 2009;207(3):E5.

29. Holland R, de Souza V, Murrata SS, Nery MJ, Bernabe PF, Otoboni JA at all : Healing Process of Dog Dental pulp after pulpotomy and Pulp covering with MTA or Portland cement .Brazilian Dental Journal 2001;12:109-113.

30. Saidon J, He J, Zhu Q, et al. Cell and tissue reactions to mineral trioxide aggregate and Portland cement. Oral Surg Oral Med Oral Pathol Radil Endod. 2003;95(4):483-489.

31. Laurent P, Camps J, De Meo M, et al Induction of specific cell responses to a Ca3SiO5-based posterior restorative material. Dent Mater. 2008;24(11):14861494.

32. Goldberg M, Pradelle-Plasse N, Tran XV, et al. Emerging trends in (bio) material research. In: Goldberg $\mathrm{M}$, ed. Biocompatability or cytotoxic effects of dental composites Chipping Norton, UK: Coxmoor Publishing Co;2008.

33. Bachoo IK, Seymour D, Brunton P. A biocompatible and bioactive replacement for dentine: is this a reality? The properties and uses of a novel calcium-based cement. Br Dent J. 2013;214(2):E5.

34. Pradelle-Plasse N, Tran $\mathrm{X}-\mathrm{V}$, Colon P. VI-2-1 Physico-chemical properties.In:Goldberg M (ed.) Biocompatibility or cytotoxic effects of dental composites. Coxmoor, Oxford. 2009;184-194.

35. Pérard M, Le Clerc J, Meary F, Pérez F, Tricot-Doleux S, Pellen-Mussi P. Spheroid model study comparing the biocompatibility of Biodentine and MTA. J Mater Sci Mater Med. 2013;24(6):152734.

36. Goldberg M, Pradelle-Plasse N, Tran $\mathrm{X}$ et al. Emerging trends in (bio)material researches. In: Goldberg M, ed. Biocompatibility or cytotoxic effects of dental composites. Oxford, UK: Coxmoor Publishing. 2009;181-203.

37. About I, Laurent P, Tecles O. Bioactivity of Biodentine ${ }^{\mathrm{TM}}$ a CA3SiO5-based Dentine Substitute. Oral session. IADR Congress. Barcelona, Spain; 2010.

38. Laurent P, Camps J, About I. Biodentine(TM) induces TGF- $\beta 1$ release from human pulp cells and early dental pulp mineralization. Int Endod J. 2012;45(5):439-48.

39. Firla MT. Dentin-Ersatzmaterial auf Basis der Active Biosilicate Technology. DZW Kompakt. 2011; 58:10-12. 